confidence these data can be used to predict adult blood pressures, and therefore those at risk from hypertension as adults, when tracking starts between 1 and 5 years.

$M$ de Swiet and the nurses helping in this study were supported by the Medical Research Council. We are grateful to Susan Cowley for help in preparing the manuscript.

\section{References}

${ }^{1}$ Rosner B, Hennekens CH, Kass EH, Miall WE. Age-specific correlation analysis of longitudinal blood pressure data. Am $\mathcal{F}$ Epidemiol 1977;106: 306-13.

2 Zinner SH, Margolius HS, Rosner B, Kass EH. Stability of blood pressure rank and urinary kallikrein concentration in childhood: an eight-year follow-up. Circulation 1978;58:908-15.

${ }^{3}$ de Swiet M, Fayers P, Shinebourne EA. Blood pressure survey in a population of newborn infants. $B r \operatorname{Med} \mathscr{f} 1976$;ii :9-11.
4 de Swiet M, Fayers P, Shinebourne EA. Systolic blood pressure in a population of infants in the first year of life-the Brompton study. Pediatrics (in press).

5 de Swiet M, Earley A, Fayers P, Shinebourne EA. Blood pressure in infancy. In: Harper PS, Muir JR, eds. Advanced medicine. 15th ed. Tunbridge Wells: Pitman Medical, 1979.

${ }^{6}$ Elseed AM, Shinebourne EA, Joseph MC. Assessment of techniques for measurement of blood pressure in infants and children. Arch Dis Child 1973;48:932-6.

7 Wright BM, Dore CF. A random zero sphygmomanometer. Lancet 1970; $\mathrm{i}: 337-8$.

8 de Swiet M, Fancourt R, Peto J. Systolic blood pressure variation during the first 6 days of life. Clin Sci Mol Med 1975;49:557-61.

${ }^{9}$ Clarke WR, Schrott HG, Leaverton PE, Conner WE, Lauer RM. Tracking of blood lipids and blood pressure in school age children: the Muscatine study. Circulation 1978;58:626-34.

${ }^{10}$ Levine RS, Hennekens CH, Klein B, et al. Tracking correlations of blood pressure levels in infancy. Pediatrics 1978;61:121-5.

(Accepted 28 April 1980)

\title{
Adverse effect of plasma exchange on anti-D production in rhesus immunisation owing to removal of inhibitory factors
}

\author{
G R BARCLAY，M AYOUB GREISS， S J URBANIAK
}

\section{Summary and conclusions}

Intensive plasma exchange was used to reduce the maternal anti-D concentration in a case of severe rhesus haemolytic disease. Initially the concentration fell from 30 to $4 \mathrm{IU} / \mathrm{ml}$, but after six exchanges it increased to $490 \mathrm{IU} / \mathrm{ml}$ despite continued exchanges, and intrauterine fetal death eventually ensued. The increase in the rate of maternal anti-D production coincided with, and may have resulted from, removal of plasma immunoregulatory factors that inhibited in-vitro lymphocyte functions.

These results suggest that the role of plasma exchange in haemolytic disease of the newborn is more complex than simply removing the antibody and that further investigations are needed.

\section{Introduction}

Plasmapheresis and plasma exchange have been used to reduce maternal anti-D concentrations in severe haemolytic disease of the newborn with differing degrees of clinical success. ${ }^{12}$ Plasma exchange may be more desirable than plasmapheresis alone, since plasmapheresis merely removes plasma while plasma exchange replaces the patient's plasma with normal plasma, replenishing plasma components and diluting maternal IgG anti-D relative to total plasma immunoglobulin. ${ }^{34}$ Pregnancy-associated plasma factors, however, will not be replaced when normal plasma is used for exchanges. Such factors might be important-for example, in maintaining maternal immunological tolerance of the "fetal allograft." We report here our observations of the effects of plasma exchange on maternal anti-D

Immunology Division, Regional Blood Transfusion Centre, Royal Infirmary, Edinburgh EH3 9HB

G R BARCLAY, BSC, MSC, senior immunologist

M AYOUB GREISS, $\mathrm{MB}, \mathrm{BCH}$, research fellow

S J URBANIAK, MRCP, PHD, consultant immunohaematologist and serum lymphocyte-regulating activity in a case of severe haemolytic disease of the newborn.

\section{Methods}

Plasma exchanges were carried out with a continuous-flow cell separator (Aminco Celltrifuge). During each exchange an average of 41 of maternal plasma was exchanged for an equal volume of normal donor fresh-frozen plasma. Maternal serum was obtained from clotted blood samples taken before and after each exchange: the serum anti-D concentration was measured by routine autoanalyser techniques, ${ }^{5}$ and serum for lymphocyte studies was decomplemented $\left(56^{\circ} \mathrm{C}\right.$ for 30 minutes) and stored at $-40^{\circ} \mathrm{C}$ for retrospective investigations.

Antibody-dependent cell-mediated cytotoxicity was determined by using column-purified peripheral blood lymphocytes as effectors ( $\mathrm{K}$-cell activity) and $\mathrm{Rh}(\mathrm{D})$-positive human red cells as targets (ratio of effector to target 10:1) in the presence of test anti-D sera as described. ${ }^{6}$

The effects of sera on lymphocyte proliferative responses to mitogens were determined by modifications of previously described culture techniques. ${ }^{7}$ Lymphocytes were cultured at $0.2 \times 10^{9} / 1$ in $150 \mu \mathrm{l}$ volumes on round-bottom microculture plates (24-ARTL, Flow Labs) and stimulated by concanavalin $\mathrm{A}(\times 3$ recrystallised in ammonium sulphate, Miles Labs) at $16 \mathrm{mg} / 1$. Cultures were supplemented with $20 \%$ decomplemented human serum:_control cultures contained pooled normal human serum alone, while test cultures contained a one to one mixture of pooled normal human serum to test serum (that is, $10 \% \mathrm{v} / \mathrm{v}$ respectively of final cultures). Responses were measured by the amount of tritiated thymidine incorporated into lymphocytes and results expressed as a percentage of the lymphocytes' response in the control culture (pooled normal human serum alone). The results shown were obtained by using maternal lymphocytes (from a sample obtained two months after intrauterine death) for the studies of antibody-dependent cell-mediated cytotoxicity and proliferation.

Case report-A 36-year-old group O, Rh-negative (cde/cde) woman presented in the 27th week of gestation of her third pregnancy with detectable serum concentrations of anti-C $+D$. Her husband's blood group was $\mathbf{B}, \mathbf{R}_{\mathbf{1}} \mathbf{R}_{\mathbf{2}}(\mathrm{CDe} / \mathrm{cDE})$. She had developed anti-C+D during her second pregnancy, when the baby was Coombs positive and mildly jaundiced but required no postnatal treatment. At presentation her antibody concentrations were: antiglobulin titre 
anti-C 1/32 and anti-D 1/32. By autoanalyser her serum anti-D concentration was $23.2 \mathrm{IU} / \mathrm{ml}$ and anti-D in amniotic fluid $2.0 \mathrm{IU} / \mathrm{ml}$, and intrauterine transfusion was carried out. By the 28th week of gestation the maternal anti-D concentration had reached $30 \mathrm{IU} / \mathrm{ml}$, and plasma exchange was started (day 0 ; figure). Amniocentesis and intrauterine transfusion were repeated during the course of plasma exchanges.

\section{Results}

Effect of plasma exchanges on maternal anti-D concentration-After six daily exchanges the maternal anti-D concentration had fallen from 30 to $4 \mathrm{IU} / \mathrm{ml}$ (figure). The rate of maternal production of anti-D, however, increased thereafter, and, despite continued exchanges, the concentration rose to a peak of $490 \mathrm{IU} / \mathrm{ml}$ at day 14 and remained substantially raised thereafter. Fetal death in utero was recorded on day 22.

Serum effects on antibody-dependent cell-mediated cytotoxicity of $D$-positive red cells-Observations have shown that the antibodydependent cell-mediated cytotoxicity of serum containing anti-D is proportional to the anti-D concentration, so that dilution reduces the "lytic potential." In the present case the opposite effect was observed (figure), since the anti-D lytic potential was greater after than before the exchanges, although the anti-D concentration had been reduced
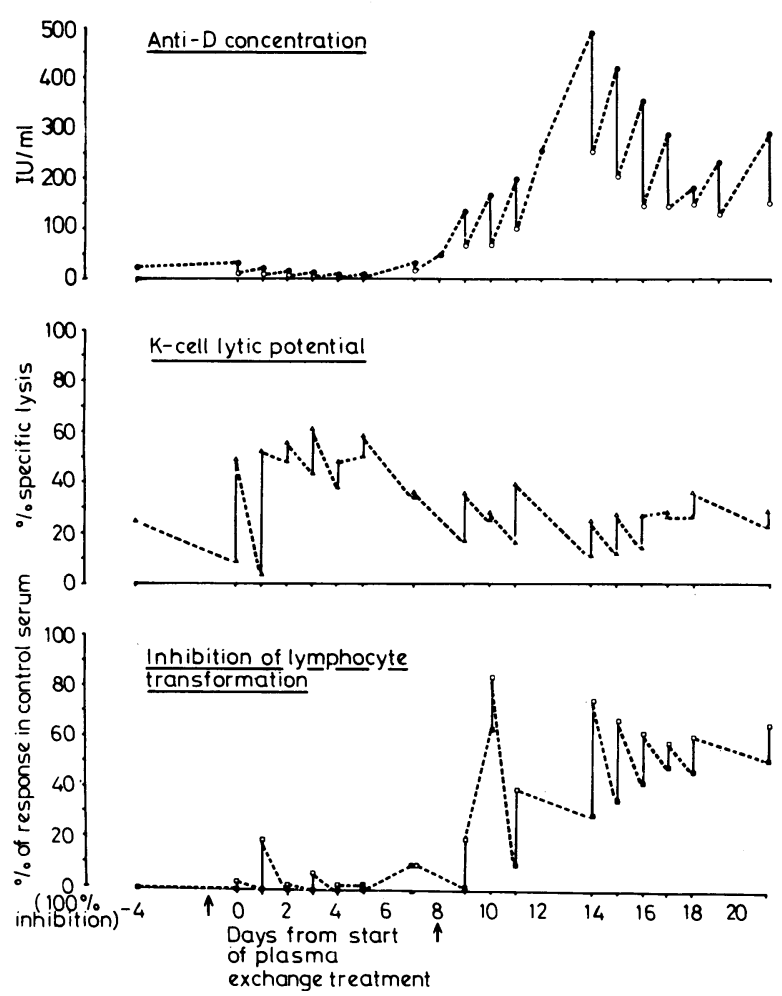

Effect of plasma exchange on maternal anti-D concentrations, serum "lytic potential" for lysis of $\mathrm{Rh}(\mathrm{D})$-positive red blood cells (by lymphocyte $\mathrm{K}$-cells), and the ability of serum to inhibit lymphocyte transformation ( ${ }^{3} \mathrm{H}$-thymidine incorporation) to concanavalin A. Days on which amniocentesis and intrauterine transfusion were carried out are indicated (arrowed). $O=$ Before exchange. $O=$ After exchange.

in the corresponding sera. No change in maternal anti-D IgG subclasses was found relating to the exchanges to account for the observed changes in lytic potential.

Serum effects on lymphocyte proliferative responses to mitogenPretreatment serum samples abolished lymphocyte transformation: sera taken early during the course of treatment also showed maximal inhibition (figure). After seven exchanges (corresponding with the time of increased anti-D production), however, the serum inhibitory activity decreased and sera obtained after exchanges were substantially less inhibitory than sera obtained before the exchanges. Titration of maximally inhibitory sera in normal pooled serum showed that the samples obtained during the first few days of treatment were more inhibitory than later samples.

\section{Discussion}

Contrary to our expectations, intensive plasma exchange did not successfully sustain a reduction in maternal concentrations of anti-D in this case of haemolytic disease of the newborn (figure). Although the anti-D concentration fell initially from 30 to under $5 \mathrm{IU} / \mathrm{ml}$, it "escaped" control and rose to $490 \mathrm{IU} / \mathrm{ml}$, and evidence suggests that this was a consequence of the plasmaexchange treatment. Inhibitory activity was present in the mother's serum before treatment, which affected lymphocyte transformation to concanavalin $\mathrm{A}$ and lymphocyte (K-cell) antibody-dependent cell-mediated cytotoxicity against $\mathrm{Rh}(\mathrm{D})$ positive red blood cells. Removing this inhibitory activity during the course of plasma exchange appeared to result in (i) an increase in the antibody-dependent cell-mediated cytotoxicity lytic potential of the patient's anti-D despite a reduction in the anti-D concentration and (ii) an increase in the rate of maternal anti-D production.

The clinical consequences of increased K-cell activity in haemolytic disease of the newborn have yet to be established. Antibody-dependent cell-mediated cytotoxicity by fetal lymphocytes may contribute to red-cell lysis in utero ${ }^{8}$; whether maternal plasma regulators cross the placenta to influence fetal lymphocyte function is not known.

An increased maternal anti-D response represents a direct threat to fetal survival. In this case the evidence suggests that removing a plasma inhibitor of lymphocyte activities allowed the rate of anti-D production to increase. Whether plasma exchange alone provoked the anti-D response or further sensitisation to fetal cells occurred at a vulnerable time in relation to the removal of the inhibitor is not clear. $R h(D)$-positive fetal cells were not detected in the maternal circulation by the Kleihauer technique at the time of intrauterine transfusion, but an additional factor may have been the presence of $\mathrm{Rh}(\mathrm{D})$-positive stroma in the fresh-frozen plasma, since this was randomly selected as regards $\mathrm{Rh}$ group.

Although plasma exchange has been used with moderate success $^{12}$ to reduce anti-D concentrations in haemolytic disease of the newborn, in such cases (and in other diseases caused or complicated by harmful antibodies) immune regulatory responses may possibly be disturbed by plasma exchange. ${ }^{9}{ }^{10}$ Isbister et $a l^{9}$ reported the development of autoantibodies with Rh-complex specificity in two mothers in whom plasma exchange was used to treat anti-D haemolytic disease of the newborn and cautioned against removing "feedback inhibition" mechanisms for controlling antibody production during plasma exchange. In animal studies plasma exchange during a primary response tends to enhance the rate of antibody production, while during a secondary response it can reduce and maintain low antibody concentration $\mathrm{s}^{10}$ : the clinical implications of this are that plasma exchange should be more effective in achieving low antibody concentrations during secondary anamnestic responses than during primary responses; this is, however, contrary to our experience in the present case, where the influence of continued antigenic stimuli may have been a complicating factor.

Sensitisation to fetal $R h(D)$ antigen in $R h(D)$-negative mothers may occur more often than indicated by the appearance of detectable concentrations of anti-D. ${ }^{11}$ Our preliminary studies indicate that group $\mathrm{O} \mathrm{Rh}(\mathrm{D})$-negative mothers who have produced detectable anti-D have a higher incidence of inhibitory activity ( 16 out of 24 women; $67 \%$ ) than do group $O$ $\mathrm{Rh}(\mathrm{D})$-negative normal (unimmunised) mothers (6 out of 150 women; $4 \%$ ), suggesting that the humoral anti-D response is subject to inhibitory influences.

Whether the inhibitory activity is produced by the mother as part of a "feedback" control mechanism or by the fetus as a protective mechanism against the effects of the anti-D is not known. Our preliminary observations on the serum of cordblood-mother pairs indicate that in general cord-blood sera are inhibitory while the corresponding maternal sera are not, suggesting that the fetus may produce its own inhibitory 
activity. In the present case, however, the inhibitory activity was more probably of maternal origin since six exchanges (total of 24 litres) were required to remove it.

We have recently undertaken plasma exchanges on several other women sensitised to anti-D with disappointing results, despite using a more intensive regimen than that reported to be successful elsewhere. ${ }^{2}$ Our present findings suggest that the role of plasma exchange in haemolytic disease of the newborn is more complex than simply removing the antibody and that further investigations are required.

We thank Dr John Scrimgeour for permission to publish details of this patient, the staff of the cell separator unit for providing samples, and the antenatal laboratory staff for measuring anti-D concentrations.

\section{References \\ ${ }^{1}$ Clarke CA, Elson CJ, Bradley J, Donohoe WTA, Lehane D, Hughes- Jones NC. Intensive plasmapheresis as a therapeutic measure in rhesus-immunised women. Lancet 1970;i:793-8. \\ ${ }^{2}$ Fraser ID, Bothamley JE, Bennet MO, et al. Intensive antenatal plasma-} pheresis in severe rhesus isoimmunisation. Lancet $1976 ; \mathrm{i}: 6-8$.
${ }^{3}$ Powell LC Jr. Intense plasmapheresis in the pregnant Rh-sensitized woman. Am $\mathcal{F}$ Obstet Gynecol 1968;101:153-70.

4 Graham-Pole JR, Barr W, Willoughby MLN. Continuous-flow exchangeplasmapheresis in severe rhesus isoimmunisation. Lancet 1974;i:1051.

5 Gunson HH, Phillips PK, Stratton F. Manipulative and inherent errors in anti-D quantitation using the AutoAnalyzer. $\mathcal{F}$ Clin Pathol 1972;25: 198-205.

${ }^{6}$ Urbaniak SJ. ADCC (K-cell) lysis of human erythrocytes sensitized with rhesus alloantibodies. I. Investigation of in vitro culture variables. Br F Haematol 1979;42:303-14.

7 Urbaniak SJ, White AG, Barclay GR, Wood SM, Kay AB. Tests of immune function. In: Weir, DM, ed. Handbook of experimental immunology. 3rd ed. Edinburgh: Blackwell, 1978.

${ }^{8}$ Urbaniak SJ. Studies on human K-cell haemolysis. PhD thesis. Edinburgh, December 1977.

9 Isbister JP, Ting A, Seeto KM. Development of Rh-specific maternal autoantibodies following intensive plasmapheresis for $\mathrm{Rh}$ immunisation during pregnancy. Vox Sang 1977;33:353-8.

10 Branda RF, Moldow CF, McCullough JJ, Jacob HS. Plasma exchange in the treatment of immune disease. Transfusion 1975;15:570-6.

${ }^{11}$ Koros AMC, Hamill EC, Depp OR. Anti-autologous erythrocyte plaqueforming cells in pregnancy: a parameter of immunoregulatory change. Vox Sang 1978;35:277-87.

\section{Summary and conclusions}

Platelets from eight patients thought clinically to have deep venous thrombosis were labelled with indium-111 and reinjected. Subsequent scanning of the patients with a wholebody scanner and imaging with a gammacamera showed focal accumulation of the label at five sites in four legs, which correlated precisely with the sites of venous thrombi identified by ascending venography.

This technique is a useful addition to methods for diagnosing venous thrombosis.

\section{Introduction}

Many techniques are used for detecting leg-vein thrombosis. ${ }^{1}$ Ascending venography is the yardstick by which all others are measured but it is often uncomfortable and carries a small but definite morbidity. ${ }^{2}{ }^{3}$ The use of fibrinogen labelled with iodine- 125 avoids the problem of discomfort and has the major advantage of being performed at the bedside. It has two major disadvantages, however. Firstly, though accuracy is good in detecting calf-vein thrombosis it diminishes in the thigh, ${ }^{1}$ and the method is useless for detecting pelvic-vein thrombosis; secondly, its value lies in detecting thrombi as they form, whereas it does not accurately identify already established thrombi.

University of Aberdeen, Foresterhill, Aberdeen AB9 2ZD

ALBERT FENECH, MD, MRCP, lecturer in medicine

P P DENDY, PHD, senior lecturer, department of biomedical physics and bioengineering

J K HUSSEY, MB, DMRD, senior registrar, department of radiology

B BENNETT, MRCP, MRCPATH, senior lecturer in medicine

A S DOUGLAS, FRCP, FRCPATH, regius professor of medicine
Platelets labelled with indium-111 have been used to estimate platelet survival, ${ }^{4-7}$ to diagnose renal transplant rejection, ${ }^{8}$ and in attempts to detect atherosclerotic plaques. ${ }^{910}$

This study was undertaken to determine whether platelets labelled with this radionuclide were useful in detecting established venous thrombosis.

\section{Materials and methods}

Platelets were labelled with indium-111 by the method of Hawker et al. ${ }^{711}$ A total of $26 \mathrm{ml}$ of venous blood was withdrawn with an 18-gauge needle, $9 \mathrm{ml}$ being added to $1 \mathrm{ml} \mathrm{3.8 \%} \mathrm{trisodium}$ citrate and used for aggregation standards and the production of platelet-poor plasma. The remaining $17 \mathrm{ml}$ was anticoagulated with $3 \mathrm{ml}$ acid citrate and the platelets separated by differential centrifugation, washed, resuspended in $\mathrm{Ca}^{++}$-free Tyrode's solution containing prostaglandin $\mathrm{E}_{1}$ (Imperial Chemical Industries Ltd), and incubated with $200-250 \mu \mathrm{Ci}$ indium-111 oxine (Radiochemical Centre) at $37^{\circ} \mathrm{C}$ for 60 seconds. After centrifugation the platelets were suspended in $5 \mathrm{ml}$ of platelet-poor plasma and reinjected into the patient 45-60 minutes after the initial venepuncture.

Scanning at slow speed was performed with an El-Scint wholebody scanner fitted with medium-energy VC-3 collimators, and the data were displayed on a VD2 videoprocessing colour display. Regions of interest were imaged with an Ohio Nuclear series 410 wide-fieldof-view gammacamera linked to a Digital Equipment Corporation Gamma-11 computer system.

Ascending venography was performed on all patients after scanning was completed and the findings reported without knowledge of the results of scanning.

\section{Results}

Eight patients were studied. Ascending venography was performed on 13 legs, and five thrombi were identified in four. The number, location, and extent of these correlated precisely with the areas in 